ENSINO E PESQUISA EM ADMINISTRAÇÃO 
ENSINO E PESQUISA EM ADMINISTRAÇÃO

\title{
O M-LEARNING COMO APOIO AO ENSINO EM ADMINISTRAÇÃO
}

\author{
M-LEARNING AS SUPPORT FOR TEACHING IN ADMINISTRATION
}

Thais Vieira de Lima

UNIGRANRIO

Fernando Filardi

IBMEC

Angilberto Sabino de Freitas

UNIGRANRIO

Data de submissão: 09 out. 2017. Data de aprovação:

10 fev. 2018. Sistema de avaliação: Double blind review.

Universidade FUMEC / FACE. Prof. Dr. Henrique Cordeiro

Martins. Prof. Dr. Cid Gonçalves Filho.

Jorge Brantes Ferreira

PUC-Rio

\section{RESUMO}

O objetivo deste estudo é apresentar um protocolo para o uso do mobile learning (m-learning) como modalidade complementar ao ensino presencial de Administração. Por meio da metodologia da Design Research, utilizou-se o Modelo para Análise Racional de Educação Móvel, com base na Teoria da Aprendizagem Experiencial, para desenvolver o artefato (protocolo), composto por 7 elementos: a) Questionário Diagnóstico; b) Ambiente Virtual de Aprendizagem (AVA); c) Comunidade de prática online; d) Reuniões presenciais de grupo; d) Realização de evento; e) Avaliação final; f) Grupo Focal. Os resultados indicam que o protocolo é adequado para a elaboração de estratégias e atividades de mobile learning. Foram encontradas evidências que reforçam o modelo teórico adotado neste estudo, principalmente devido aos seus aspectos sociais: interação; promoção de contextos autênticos; e formação de comunidades de aprendizagem. Os resultados também apontam barreiras no uso do m-learning, como: a resistência à mudança; o baixo grau de criticidade dos estudantes; e a exigência de uma sólida formação didático-pedagógica do professor universitário. $O$ protocolo proposto pretende contribuir com uma nova perspectiva sobre o uso da tecnologia móvel no processo de ensino-aprendizagem.

PALAVRAS-CHAVE

Mobile Learning. Inovação. Design Research. Ensino Superior. Professores 


\section{ABSTRACT}

This study aims to propose a protocol for the use of mobile learning as a complementary learning method to traditional lectures for the teaching of Business Administration in Higher Education. Through the employment of Design Research and the Framework for the Rational Analysis of Mobile Education, based on the Experiential Learning Theory, a protocol was developed, composed of 7 elements: a) Diagnostic Questionnaire; b) Virtual Learning Environment (VLE); c) Online Practice Community; d) Group face-to-face meetings; d) Event Accomplishment; e) Final evaluation; f) Focus Group. The results indicate that the proposed protocol is adequate to develop teaching strategies and activities employing mobile learning, with evidence corroborating the theoretical framework adopted in this study, with particular significance to its social aspects: interaction, contextually and the fostering of learning communities. The results also point to barriers that might hinder m-learning usage, such as resistance to change, low levels of critical thinking among students and the requirement of solid pedagogical knowledge by higher education instructors. The proposed protocol aims to contribute with a fresh perspective on the use of mobile technology to enhance learning, suggesting best practices that might help its usage as a teaching tool.

\section{KEYWORDS}

Mobile Learning. Innovation. Design Research. Higher Education. Teachers

\section{INTRODUÇÃO}

As tecnologias móveis tornaram-se comuns em nossa sociedade. Atualmente, são mais de 277 milhões de celulares ativos no Brasil, de acordo com dados de 2014 divulgados pela Agência Nacional de Telecomunicações (ANATEL). Conforme a reguladora, a média nacional equivale a I,37 aparelho celular ativo por habitante (http://www.anatel.gov.br). Segundo o relatório da consultoria IDC (20I5), o Brasil ocupa atualmente a quarta colocação entre os maiores mercados do mundo, atrás de China, Estados Unidos e Índia (http:// www.br.idclatin.com). Por ocuparem esse papel quase indispensável na vida cotidiana, os dispositivos móveis podem vir a desempenhar uma função crítica no processo de ensino-aprendizagem, caracterizando o que se pode ser chamado de mobile learning ou m-learning (FERREIRA et al., 20l3).

O mobile learning ou m-learning pode ser entendido como um sistema de aprendizagem apoiado pelo uso de dispositivos móveis, como telefones celulares, smartphones e tablets, caracterizado pelo acesso à informação e ao conhecimento em qualquer lugar e a qualquer momento, sendo capaz de promover uma aprendizagem contextualizada, trazendo conveniência, controle e maior autonomia para o estudante (TRAXLER, 2007; SHARPLE et al., 2007).

Essas potencialidades proporcionadas pelo uso das tecnologias móveis como recurso para a educação têm instigado as Instituições de Ensino Superior (IESs) a 
buscarem novas linguagens e a descobrirem alternativas ao processo de ensino -aprendizagem (SCHLEMMER et al., 20I5). $\mathrm{Na}$ possibilidade de adotarem o m-learning, algumas IESs precisam procurar, além de criar um ambiente mais alinhado com a nova sociedade do conhecimento, desenvolver outras possibilidades de ensino mais adequadas ao perfil do discente atual, imerso nesta era digital (FREITAS, 2009; FREITAS; BANDEIRA-DE-MELLO, 20I2).

Apesar do m-learning ser uma tecnologia educacional disponível há algum tempo, ainda demanda investigação mais rigorosa, em função da necessidade de preparar os indivíduos, não só para o uso das ferramentas tecnológicas no sentido instrumental, mas também de prepará-los no aspecto pedagógico, buscando maior imersão nas diferenças entre os modelos presencial e virtual (FERREIRA et al., 20I3). Para Chu et al. (20I0), um grande problema ocorre devido à falta de estratégias ou ferramentas de aprendizagem adequadas para ajudar os estudantes a adquirirem conhecimento usando dispositivos móveis.

Assim, este estudo tem por objetivo propor a elaboração de um protocolo que possa usar o m-learning como suporte ao processo de ensino-aprendizagem em cursos de graduação de administração. Aplicando o Modelo para Análise Racional de Educação Móvel (FRAME), proposto por Koole (2009), e com base na Teoria da Aprendizagem Experiencial de Kolb (1976), é proposto um protocolo para a elaboração de estratégias e atividades de m-learning com 62 estudantes de graduação em Administração. Diferentes potencialidades do m-learning e dinâmicas de aprendizagem experiencial foram exploradas durante a aplicação empírica do artefato.

\section{FUNDAMENTAÇÃO TEÓRICA}

O mobile learning ou m-learning é uma modalidade de ensino e aprendizagem que abre um leque de novas oportunidades para a educação. Fatores como o acesso rápido e fácil à informação em um único dispositivo ao qual as pessoas já estão familiarizadas e afetivamente ligadas podem facilitar o desenvolvimento dessa modalidade, assim como diversos outros aspectos que impulsionam o m-learning (SHIH;MILLS, 2007). Suas principais potencialidades são: (I) possibilidades de contextualização; (2) ubiquidade; (3) autonomia e controle; (4) aproveitamento do tempo; e (5) a colaboração (SHARPLES et al., 2007; TRAXLER, 2007; FERREIRA et al., 20I3).

Mesmo diante dessas potencialidades, a disseminação do uso do m-learning tem enfrentado barreiras e limitações que também precisam ser consideradas, tais como: (I) barreiras técnicas (baixa qualidade de conexão das redes móveis, capacidade limitada de armazenamento de dados dos dispositivos móveis, etc.); (2) barreiras ergonômicas (tela pequena e a dificuldade em digitar textos longos); (3) barreiras culturais (necessidade de "alfabetização digital", resistência à mudança, etc.); (4) a necessidade de um planejamento elaborado, capaz de combinar diferentes métodos de ensino; e (5) a ausência de um modelo pedagógico específico para essa modalidade (SCHLEMMER et al., 2007; FERREIRA et al., 20I3).

\section{Práticas de mobile learning}

Ao revisar a literatura, é possível identificar uma série de diferentes práticas de m-learning, desde aplicações simples como o uso de SMS, e-mail, redes sociais e interação com ambientes virtuais de aprendizagem (AVA) para apoiar o ensino tradi- 
cional, até o uso de sistemas sofisticados e especificamente desenvolvidos para essa modalidade de educação como: (I) a criação de aplicativos específicos; (2) ○ uso de tecnologia de radiofrequência (RFID); e (3) mundos virtuais em terceira dimensão (MV3D) entre outras práticas (ver, por exemplo: $\mathrm{CHU}$ et al., 20I0; FERREIRA et al., 20I3; MACHADO et al., 20I3).

Percebe-se que existem muitas aplicações possíveis para o uso das tecnologias móveis, que podem incluir o trabalho, o lazer e a aprendizagem formal ou informal. Porém, é importante lembrar que ao se adotar o m-learning é necessário priorizar - aspecto didático-pedagógico, para que sejam consideradas as diferentes características ligadas a cada prática, buscando sua adequação aos diversos contextos de aprendizagem (FERREIRA et al., 20l3).

\section{Modelo Teórico FRAME}

Para a elaboração do artefato (protocolo) proposto nesta pesquisa, foi utilizado o
Modelo para Análise Racional de Educação Móvel (FRAME) de Marguerite Koole (2009), que entende o m-learning como um processo resultante da convergência das tecnologias móveis com a capacidade de aprendizagem dos indivíduos e de interação social. Esse modelo (figura I) trata de questões pedagógicas, como a sobrecarga de informação, navegação, conhecimento e aprendizagem colaborativa.

O modelo FRAME, com ênfase no construtivismo, destaca $\circ$ papel da tecnologia, em que o dispositivo móvel é um componente ativo e em pé de igualdade com a aprendizagem e com os processos sociais. A palavra racional refere-se à crença de que a razão é a fonte primária de conhecimento e que a realidade é construída ao invés de descoberta (KOOLE, 2009). O modelo descreve um modo de aprendizagem no qual o aprendiz pode mover-se por diferentes locais físicos e virtuais, e assim participar e interagir com outras pessoas, informações ou sistemas, em qualquer lugar e a qualquer hora.

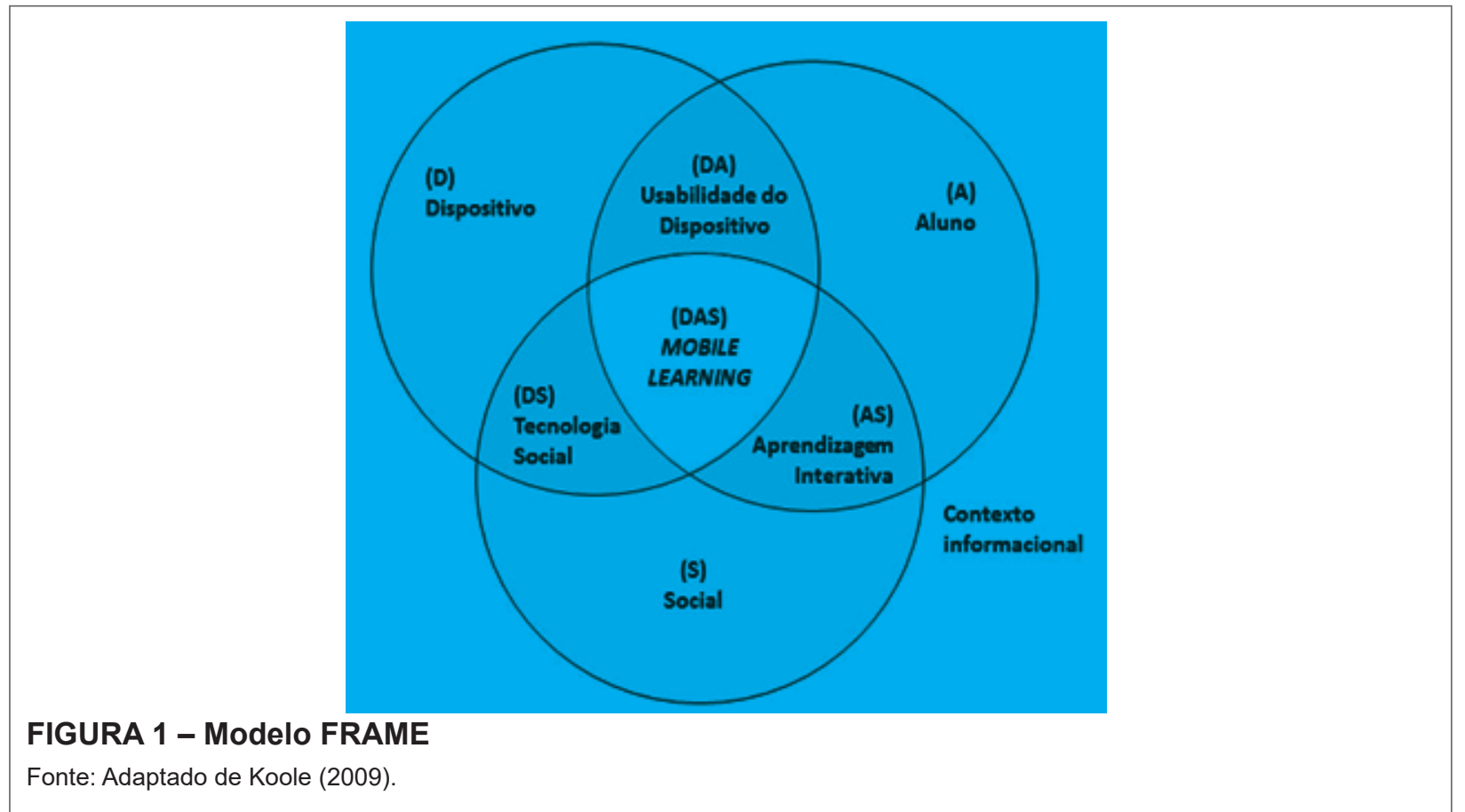

32 R. Adm. FACES Journal Belo Horizonte v. 17 n. 3 p. 28-47 jul./set. 2018. ISSN 1984-6975 (online). ISSN 1517-8900 (Impressa) http://dx.doi.org/10.21714/1984-6975FACES2018V17N3ART5571 


\section{Aspecto Dispositivo (D)}

O Aspecto Dispositivo (D) refere-se às características físicas, técnicas e funcionais de um dispositivo móvel (quadro I). Essas características possuem um impacto significativo sobre os níveis de conforto físico e psicológico dos usuários.

\section{Aspecto Aluno (A)}

O Aspecto Aluno (A) leva em conta as habilidades cognitivas do indivíduo, a memória, o conhecimento prévio, as emoções e as motivações possíveis (quadro 2).

\section{Aspecto Social (S)}

O Aspecto Social leva em conta os processos de interação social e de cooperação (quadro 3). Regras de cooperação são determinadas pela cultura do aluno ou pela cultura em que a interação acontece. No m-learning, essa cultura pode ser física ou virtual.

\section{Interseção Usabilidade do Dispositi- vo (DA)}

A Usabilidade do Dispositivo relaciona as características dos dispositivos móveis para tarefas cognitivas com a manipulação e armazenamento de informações (quadro 4).

\section{QUADRO 1 - Aspecto Dispositivo}

\begin{tabular}{|l|l|l|}
\hline \multicolumn{2}{|c|}{ Critério } & \multicolumn{1}{|c|}{ Exemplos e Conceitos } \\
\hline Características físicas & $\begin{array}{l}\text { Tamanho, peso, localização de botões e teclas, re- } \\
\text { quisito mão direita / esquerda. }\end{array}$ & $\begin{array}{l}\text { Afeta o modo como o usuário pode manipular } \\
\text { o dispositivo. }\end{array}$ \\
\hline $\begin{array}{l}\text { Capacidade de entrada } \\
\text { (input) para periféricos }\end{array}$ & $\begin{array}{l}\text { Conectar teclado, mouse, touchscreen, reconheci- } \\
\text { mento de voz, etc. ao dispositivo móvel. }\end{array}$ & $\begin{array}{l}\text { Muitas vezes não permitem que periféricos se- } \\
\text { jam conectados ao aparelho. }\end{array}$ \\
\hline $\begin{array}{l}\text { Capacidade de saída } \\
\text { (output) para periféricos }\end{array}$ & $\begin{array}{l}\text { É a capacidade de conectar o dispositivo móvel a } \\
\text { monitores, alto-falantes, etc. }\end{array}$ & $\begin{array}{l}\text { Muitas vezes possuem limitações nos meca- } \\
\text { nismos de saída para conectar periféricos. }\end{array}$ \\
\hline $\begin{array}{l}\text { Agilidade do processador } \\
\text { Taxas de resposta; velocidade. }\end{array}$ & $\begin{array}{l}\text { A velocidade de resposta curta ou longa pode } \\
\text { afetar as taxas de erro. }\end{array}$ \\
\hline
\end{tabular}

Fonte: Adaptado de Koole (2009).

QUADRO 2 - Aspecto Aluno

\begin{tabular}{|c|c|c|}
\hline \multicolumn{3}{|c|}{ CATEGORIAS DE ANÁLISE - ALUNO (A) } \\
\hline Critério & Exemplos e Conceitos & Comentários \\
\hline Conhecimento prévio & $\begin{array}{l}\text { Estruturas cognitivas prontas na memória; ancora- } \\
\text { gem de ideias. }\end{array}$ & Facilita a compreensão de novos conceitos. \\
\hline Memorização & $\begin{array}{l}\text { As técnicas para a codificação, como o uso de pis- } \\
\text { tas contextuais: categorização, mnemônicos, me- } \\
\text { mória semântica e episódica, tátil, auditiva, olfativa, } \\
\text { imaginativa, visual, cinestésica. }\end{array}$ & $\begin{array}{l}\text { Incluir recursos multimídia;fornece vários ese } \\
\text { tímulos que podem ajudar o aluno a entender } \\
\text { conceitos. }\end{array}$ \\
\hline $\begin{array}{l}\text { Contextualização e } \\
\text { transferência }\end{array}$ & Inerte $\mathrm{x}$ conhecimento ativo. & $\begin{array}{l}\text { O uso ativo da informação para ajudar o aluno } \\
\text { a lembrar, entender e transferir conceitos para } \\
\text { contextos variados. }\end{array}$ \\
\hline $\begin{array}{l}\text { Aprendizagem pela } \\
\text { descoberta }\end{array}$ & $\begin{array}{l}\text { Aplicação de procedimentos e conceitos a uma } \\
\text { nova situação; soluções para problemas novos. }\end{array}$ & $\begin{array}{l}\text { Pode estimular o aluno a desenvolver habilida- } \\
\text { des para filtrar e reconhecer informações rele- } \\
\text { vantes. }\end{array}$ \\
\hline Emoções e motivações & $\begin{array}{l}\text { Sentimentos do aluno em relação a uma tarefa; ra- } \\
\text { zões para realizar uma tarefa. }\end{array}$ & $\begin{array}{l}\text { A vontade do aluno pode influenciar seu estado } \\
\text { emocional ou desejo de realizar uma tarefa. }\end{array}$ \\
\hline
\end{tabular}

Fonte: Adaptado de Koole (2009). 
QUADRO 3 - Aspecto Social

\begin{tabular}{|c|l|l|}
\hline \multicolumn{3}{|c|}{ CATEGORIAS DE ANÁLISE - SOCIAL (S) } \\
\hline \multicolumn{1}{|c|}{ Critério } & \multicolumn{1}{|c|}{ Exemplos e Conceitos } & \multicolumn{1}{c|}{ Comentários } \\
\hline $\begin{array}{l}\text { Conversação e } \\
\text { cooperação }\end{array}$ & $\begin{array}{l}\text { Constrangimentos sociais; 4 regras máximas: quantidade, } \\
\text { qualidade, relação e modo. A comunicação deve ocorrer em } \\
\text { quantidade adequada, com um bom nível de clareza e num } \\
\text { ambiente capaz de estimular a participação e acolher a di- } \\
\text { versidade de opiniões. }\end{array}$ & $\begin{array}{l}\text { Afeta qualidade e quantidade da comunica- } \\
\text { quando não é encontrada qualquer uma das } \\
\text { quatro máximas. }\end{array}$ \\
\hline Interação social & $\begin{array}{l}\text { Conversa como atividade de cooperação; partilha de signos } \\
\text { e símbolos. }\end{array}$ & $\begin{array}{l}\text { Acordo sobre o significado dos sinais e símbo- } \\
\text { los pode afetar e reforçar o comportamento, as } \\
\text { crenças sociais e culturais. }\end{array}$ \\
\hline
\end{tabular}

Fonte: Adaptado de Koole (2009).

QUADRO 4 - Interseção Usabilidade do Dispositivo (DA)

\begin{tabular}{|c|c|c|}
\hline \multicolumn{3}{|c|}{ CATEGORIAS DE ANÁLISE - USABILIDADE DO DISPOSITIVO (DA) } \\
\hline Critério & Exemplos e Conceitos & Comentários \\
\hline Portabilidade & Portabilidade e durabilidade do dispositivo. & $\begin{array}{l}\text { Afeta a capacidade do usuário de levar o disposi- } \\
\text { tivo para diferentes ambientes e climas. }\end{array}$ \\
\hline $\begin{array}{l}\text { Disponibilidade da } \\
\text { informação }\end{array}$ & $\begin{array}{l}\text { A qualquer hora e em qualquer lugar, acessar infor- } \\
\text { mações armazenadas em um dispositivo. }\end{array}$ & $\begin{array}{l}\text { Permite uma aprendizagem em tempo real; as } \\
\text { informações acompanham o usuário. }\end{array}$ \\
\hline Conforto psicológico & $\begin{array}{l}\text { Learnability: facilidade do usuário de aprender e } \\
\text { conseguir usar o dispositivo o mais rápido possível; } \\
\text { transparência e memorabilidade: quando o usuário } \\
\text { consegue lembrar como usa, mesmo após um perío- } \\
\text { do sem usar. }\end{array}$ & $\begin{array}{l}\text { Afeta a carga cognitiva e a velocidade com a qual } \\
\text { os usuários podem executar tarefas. Fragmentar } \\
\text { a informação, simplificar telas e diminuir as ações } \\
\text { necessárias para realizar uma tarefa podem re- } \\
\text { duzir a carga cognitiva. }\end{array}$ \\
\hline Satisfação & $\begin{array}{l}\text { Design da interface e do dispositivo; funcionalidade; } \\
\text { estilo cognitivo preferido. }\end{array}$ & $\begin{array}{l}\text { Como satisfação e prazer são altamente pes- } \\
\text { soais e culturalmente determinados. É muito ditu } \\
\text { fícil de prever. }\end{array}$ \\
\hline
\end{tabular}

Fonte: Adaptado de Koole (2009).

\section{Interseção Tecnologia Social (DS)}

A Interseção Tecnologia Social descreve como os dispositivos móveis permitem a comunicação e a colaboração entre várias pessoas e sistemas (quadro 5). Praticantes do m-learning devem considerar o fornecimento de repositórios digitais ou ambientes virtuais que auxiliem os alunos a se comunicar, embora estejam fisicamente e temporalmente separados.

\section{InterseçãoAprendizagem Interativa (AS)}

A Interseção Aprendizagem Interativa representa uma síntese das teorias de ensino-aprendizagem, mas baseia-se fortemente na filosofia do construtivismo social (quadro 6).

\section{Interseção Processo de M-Learning (DAS)}

A Interseção principal do modelo FRAME resulta da integração dos Aspectos do Dispositivo (D), do Aluno (A) e dos Aspectos Sociais (S). $\bigcirc$ m-learning promove uma maior colaboração entre os alunos, o acesso à informação e uma contextualização mais profunda da aprendizagem (quadro 7).

\section{Teoria da Aprendizagem Experiencial}

A metodologia ativa diferencia-se do método clássico de ensino. Enquanto a segunda valoriza a transmissão de conhecimentos e a memorização, a primeira entende a reflexão experiencial como uma importante

34 R. Adm. FACES Journal Belo Horizonte v. 17 n. 3 p. 28-47 jul./set. 2018. ISSN 1984-6975 (online). ISSN 1517-8900 (Impressa)

http://dx.doi.org/10.21714/1984-6975FACES2018V17N3ART5571 
QUADRO 5 - Tecnologia Social (DS)

\begin{tabular}{|l|l|l|}
\hline \multicolumn{2}{|c|}{ CATEGORIAS DE ANÁLISE - TECNOLOGIA SOCIAL (DS) } \\
\hline \multicolumn{1}{|c|}{ Critério } & \multicolumn{1}{|c|}{ Exemplos e Conceitos } & \multicolumn{1}{c|}{ Comentários } \\
\hline $\begin{array}{l}\text { Networking do disposi- } \\
\text { tivo (wi-fi, conectivida- } \\
\text { de, etc.) }\end{array}$ & $\begin{array}{l}\text { Redes Locais Sem Fio (WLAN), software de sin- } \\
\text { cronização, wireless fidelity (Wi-Fi), conectividade } \\
\text { celular. }\end{array}$ & $\begin{array}{l}\text { Os vários padrões de conectividade permitem que } \\
\text { os usuários se conectem a outros usuários, sistemas } \\
\text { e informações, sendo importante o uso de conexões } \\
\text { em banda larga. }\end{array}$ \\
\hline $\begin{array}{l}\text { Conectividade do } \\
\text { sistema }\end{array}$ & Acesso à internet e transferência de documentos & $\begin{array}{l}\text { Os usuários devem ser capazes de trocar documen- } \\
\text { tos e informações, dentro e entre os sistemas. }\end{array}$ \\
\hline $\begin{array}{l}\text { Ferramentas de } \\
\text { colaboração }\end{array}$ & $\begin{array}{l}\text { Ferramentas compartilhadas, como calendários, } \\
\text { criação de documentos e ferramentas de geren- } \\
\text { ciamento de projetos. }\end{array}$ & $\begin{array}{l}\text { As ferramentas de colaboração permitem a coautoria } \\
\text { de documentos; a coordenação das tarefas; a realiza- } \\
\text { ção de reuniões de forma síncrona ou assíncrona e a } \\
\text { tomada de decisões. }\end{array}$ \\
\hline
\end{tabular}

Fonte: Adaptado de Koole (2009).

\section{QUADRO 6 - Aprendizagem Interativa (AS)}

\begin{tabular}{|l|l|l|}
\hline \multicolumn{3}{|c|}{ CATEGORIAS DE ANÁLISE - APRENDIZAGEM INTERATIVA (AS) } \\
\hline \multicolumn{1}{|c|}{ Critério } & \multicolumn{1}{|c|}{ Exemplos e Conceitos } & \multicolumn{1}{c|}{ Comentários } \\
\hline Interação & $\begin{array}{l}\text { Aluno-aluno; aluno-instrutor; aluno-conteú- } \\
\text { do; Aprendizagem Baseada em Computador } \\
\text { (ABC); sistemas tutores inteligentes. }\end{array}$ & $\begin{array}{l}\text { Diferentes tipos de interação podem estimular a aprendi- } \\
\text { zagem em diferentes níveis de eficácia, dependendo da } \\
\text { situação, do aluno e da tarefa. }\end{array}$ \\
\hline Cognição situada & Autenticidade do contexto e audiência. & $\begin{array}{l}\text { Uma proposição real e o público disponível para uma ta- } \\
\text { refa de aprendizagem podem aumentar a motivação dos } \\
\text { alunos. }\end{array}$ \\
\hline $\begin{array}{l}\text { Comunidade de } \\
\text { aprendizagem }\end{array}$ & $\begin{array}{l}\text { Aprendizagens cognitivas, diálogo, resolução } \\
\text { de problemas, comunidades de prática. }\end{array}$ & $\begin{array}{l}\text { Os alunos trabalham uns com os outros, num esforço para } \\
\text { alcançar objetivos mútuos. }\end{array}$ \\
\hline
\end{tabular}

Fonte: Adaptado de Koole (2009)

QUADRO 7 - Interseção Processo de Mobile Learning (DAS)

\begin{tabular}{|c|c|c|}
\hline \multicolumn{3}{|c|}{ CATEGORIAS DE ANÁLISE - INTERSEÇÃO PROCESSO DE MOBILE LEARNING (DAS) } \\
\hline Critério & Exemplos e Conceitos & Comentários \\
\hline Mediação & $\begin{array}{l}\text { Ciclo Tarefa-Artefato (Task arte- } \\
\text { fact cycle) mediação }\end{array}$ & $\begin{array}{l}\text { A natureza da própria interação muda a forma como os alunos intera- } \\
\text { gem entre si, seus ambientes, ferramentas e informações. }\end{array}$ \\
\hline $\begin{array}{l}\text { Navegação no co- } \\
\text { nhecimento }\end{array}$ & $\begin{array}{l}\text { Produção de conhecimento vs. } \\
\text { navegação no conhecimento. }\end{array}$ & $\begin{array}{l}\text { Na produção do conhecimento, os professores determinam quais e } \\
\text { como as informações devem ser aprendidas. Na navegação no conheci- } \\
\text { mento, os alunos adquirem habilidades para selecionar adequadamen- } \\
\text { te, manipular e aplicar informações para as suas próprias situações e } \\
\text { necessidades. }\end{array}$ \\
\hline $\begin{array}{l}\text { Acesso à informação } \\
\text { e seleção }\end{array}$ & $\begin{array}{l}\text { Ruídos de comunicação, identi- } \\
\text { ficação de padrões e relaciona- } \\
\text { mentos, relevância e precisão. }\end{array}$ & $\begin{array}{l}\text { Como a quantidade de informação disponível aumenta, os alunos de- } \\
\text { vem redobrar os seus esforços, no sentido de reconhecer e avaliar a } \\
\text { adequação e a precisão das informações. }\end{array}$ \\
\hline
\end{tabular}

Fonte: Adaptado de Koole (2009).

ferramenta de aprendizagem. $O$ conceito de aprendizagem experiencial pode ser definido como "o processo pelo qual o conhecimento é criado através da transformação da experiência" (KOLB, 1984, p. 4I).Ao alu- no é preciso apresentar situações para promover experiências a partir das quais ele possa aprender. $O$ indivíduo é visto como agente no processo de aprendizagem, como um sujeito que tem conhecimento prévio 
e um pensador que intervém na realidade, interagindo e estabelecendo relacionamentos. Desse modo, o estudante passa a ocupar o centro do processo de aprendizagem. O uso de aprendizagem experiencial implica o desejo de examinar as forças emocionais, sociais e políticas que moldam a aprendizagem (KOLB, 1984).

Dentro desse contexto, o m-learning oferece muitas oportunidades de aplicação de metodologias ativas de aprendizagem. É o caso das aulas em laboratório, oficina, tarefa em grupo, trabalho em equipe dentro e fora do ambiente escolar, visita técnica e desenvolvimento de projeto. Essas atividades tendem a ser naturalmente participativas e promovem o envolvimento do aluno no processo de aprendizagem.

Assim como na Teoria da Aprendizagem Experiencial (TAE), o Modelo FRAME leva em consideração tanto os processos de aprendizagem sociais e pessoais quanto as características técnicas dos dispositivos móveis. Esse modelo privilegia a autonomia do estudante, a interação, a colaboração, o acesso rápido e fácil à informação e promove uma contextualização mais aprofundada do processo de ensino e aprendizagem (KOOLE, 2009 KEARNEY; BURDEN; RAI, 20I5).

\section{METODOLOGIA}

A metodologia adotada nesta pesquisa foi a Design Research (TAKEDA et al., 1990). Um método de pesquisa que utiliza a teoria para a construção de artefatos úteis. De acordo com Freitas Junior et al. (20I5), na Design Research o pesquisador está inserido numa realidade, identificando, compreendendo e propondo soluções para problemas ou necessidades reais. Ele gerencia o processo de pesquisa, propõe o problema a ser solucionado e, juntamente com os participantes, elabora sugestões, testa, avalia, refina e melhora as propostas iniciais, buscando encontrar a solução mais adequada, que contribua tanto no aspecto teórico quanto prático para a geração de novos conhecimentos.

$\mathrm{O}$ artefato desenvolvido e aplicado em 62 estudantes da disciplina Gestão de Serviço do curso de graduação em Administração de um centro universitário privado do Rio de Janeiro foi um protocolo para o desenvolvimento de estratégias e atividades de m-learning. Para a escolha da IES participante, foram definidos alguns requisitos básicos como: ( $\mathrm{I}$ ) a existência de rede sem fio de acesso à internet disponível para alunos e professores em todo o campus; (2) a qualidade e capacidade da rede; (3) política de uso; (4) perfil do aluno e dos professores; e (5) incentivo ao uso da tecnologia móvel.

O artefato (protocolo) foi composto por 7 elementos:

I. Questionário Diagnóstico - instrumento qualitativo e quantitativo, autoadministrado, para avaliar as experiências prévias dos alunos com os dispositivos móveis. Aplicado antes de iniciar o processo de m-learning.

2. Ambiente Virtual de Aprendizagem (AVA) - uso do AVA da IES para disponibilizar os materiais apresentados e produzidos pelos alunos, professor da disciplina e pesquisadora.

3. Comunidade de prática online grupos de trabalho online para aprofundamento dos conteúdos tratados em sala de aula e para acompanhamento da atividade prática proposta na disciplina Gestão de Serviços. 
Os alunos foram divididos em sete grupos para prestarem um serviço à comunidade local em um evento promovido pelo centro universitário. Foram incentivadas a aprendizagem em contextos autênticos, a colaboração e a resolução de problemas de forma cooperativa.

4. Reuniões presenciais de grupo - encontros de 15 minutos ao final das aulas presenciais semanais para acompanhamento das atividades propostas.

5. Realização de evento - cada grupo escolheu um tema para prestar um serviço à comunidade. Desde a escolha do tema até o registro por foto e vídeo no dia evento, todas as atividades foram feitas com o auxílio do dispositivo móvel e as informações e dúvidas foram imediatamente compartilhadas com o grupo de trabalho online. Os grupos elaboraram materiais impressos, promoveram palestras e participaram da organização do evento. Os serviços oferecidos por cada grupo foram estruturados de acordo com o conteúdo apresentado em sala de aula sobre qualidade na gestão de serviços.

6. Avaliação final - questionário qualitativo e quantitativo, autoadministrado, respondido pelos alunos sobre suas impressões a respeito do uso do m-learning como estratégia complementar à modalidade presencial de ensino.

7. Grupo Focal - coleta de dados realizada com 5 alunos participantes e um observador para aperfeiçoamento do artefato (protocolo). Nesse momento, surgiram questões complementa- res como: (I) necessidade do professor adotar uma postura democrática e dialógica; (2) dificuldade para acompanhar o alto fluxo de mensagens; e (3) grupos de trabalho online inativos e desmotivados.

Com o intuito de promover o ambiente necessário para o desenvolvimento do protocolo, foi construído um cronograma de atividades, alinhado com o plano de aula do professor da IES, que estabeleceu para cada encontro presencial um objetivo apoiado pelas ações de m-learning (quadro 8).

As atividades previstas foram agrupadas em 6 etapas: Observação, Sensibilização, Escolha do tema, Fechamento dos materiais, Acertos finais e Realização do evento.

Inicialmente, todos os dados coletados a partir dos questionários, grupo focal, e-mails, mensagens de texto, áudio, vídeo e fotografias foram organizados e arquivados fisicamente e eletronicamente. Após essa etapa, como se trata de um estudo multimétodo (qualitativo e quantitativo), foram utilizadas técnicas de análise de conteúdo (BARDIN, 1995) para tratar os dados qualitativos e técnicas estatísticas descritivas para os dados quantitativos. A opção por uma abordagem multimétodo permitiu uma análise mais aprofundada dos aspectos relacionados ao processo e a como a pesquisa se integra ao fenômeno do uso das tecnologias móveis no ambiente de ensino-aprendizagem em Administração.

\section{PROCESSO DE CONSTRUÇÃO DO PROTOCOLO}

O processo de construção do artefato (figura 2) partiu da revisão da literatura de teorias e modelos que contribuíssem para o entendimento da adoção do m-learning e suas práticas.A partir de então, adotou-se o 


\section{QUADRO 8 - Atividades de mobile learning desenvolvidas durante o estudo e objetivos dos encontros presenciais}

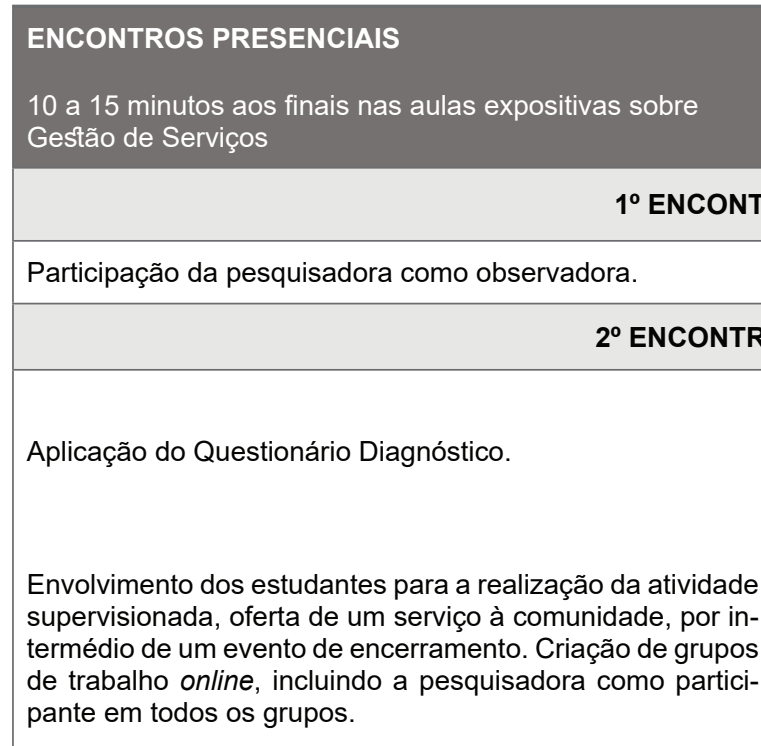

\section{$3^{\circ}$ ENCONTRO - ESCOLHA DO TEMA}

Após pesquisa e observação realizada por cada grupo sobre as realidades que gostariam de abordar, foram escoIhidos os temas a serem trabalhados por cada equipe. A saber: Câncer de mama e próstata; Prevenção do alcoolismo; Economia de água; Lixo eletrônico; Ervas fitoterápicas; Prevenção de doenças de 0 a 80 anos; e Campanha para arrecadação de alimentos.

\section{$4^{\circ}$ ENCONTRO - FECHAMENTO DOS MATERIAIS}

Resolução em grupo sobre os textos a serem divulgados nos panfletos, os equipamentos necessários, os convidados externos e palestrantes, e a forma como o serviço seria prestado nos estandes, seguindo as indicações presentes na literatura estudada no curso sobre qualidade na gestão de serviços.

\section{$5^{\circ}$ ENCONTRO - ACERTOS FINAIS}

Estudantes fazem prova da disciplina, respondem o Questionário de Avaliação Final e combinam os últimos acertos para a oferta dos serviços nos estandes durante o evento.

Definição do grupo sobre panfletos, brindes, decoração, equipamentos, palestrantes, convidados, etc. dos grupos para a escolha do tema a ser desenvolvido.

Envio de quiz a respeito do conteúdo visto em sala e sua relação com a qualidade do serviço a ser prestado pelos alunos no evento final.

Envio de sugestões e modelos para auxiliar os alunos a organizarem as Debate para resolução conjunta dos problemas.

Envio do Drops semanal.

Esclarecimento de dúvidas a respeito do conteúdo da disciplina, durante a semana de prova. Envio do Drops semanal.

\section{$6^{\circ}$ ENCONTRO - REALIZAÇÃO DO EVENTO}

Alunos realizam evento e aplicam pesquisa de satisfação dos serviços, de acordo com os critérios estabelecidos na literatura do curso.

\footnotetext{
Fonte: Elaborado pelos autores.
}

Intensa troca de mensagens entre os grupos e a organização do evento; registro e compartilhamento de fotos e vídeos entre os grupos, durante o evento, para a elaboração de um relatório final; fotografia das listas de presença ao evento para evitar perda das informações; lembrete e auxílio para elaboração dos relatórios de cada grupo para envio ao AVA, como forma de entrega ao professor da disciplina; elaboração conjunta e compartilhamento de vídeo comemorativo, com a participação de todos os grupos de trabalho no evento de encerramento.

Envio do vídeo de sensibilização para a realização do evento de Envio de link para acesso ao material complementar (brainstorm e mento troca de informações, pesquisa, colaboração e compartilha-

Acompanhamento das sugestões e participação no debate para escolha do tema a ser trabalhado.

Envio de material de apoio com os principais itens do conteúdo abormapa mental) aos grupos de trabalho para auxiliar na organização das ideias.

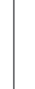


Modelo para Análise Racional de Educação Móvel (FRAME) de Koole (2009), que tem como finalidade auxiliar no desenvolvimento de materiais e de estratégias de ensino -aprendizagem com uso de mobile learning. Como as potencialidades do m-learning sugerem a adoção de metodologias ativas, escolheu-se a Teoria da Aprendizagem Experiencial (KOLB, 1976) como abordagem pedagógica. Tanto o desenvolvimento quanto a aplicação das atividades buscaram adequação à metodologia de ensino e ao curso de Administração. A fim de propor o uso do m-learning em tarefas pedagogicamente relevantes, isto é, que trouxessem contexto, conveniência, controle e autonomia para o aluno, buscou-se conhecer as principais práticas de m-learning descritas na literatura da área, objetivando as escolhas mais ajustadas ao propósito desta pesquisa. Para que fossem garantidos os critérios de funcionalidade do artefato, partiu-se das limitações dessa modalidade de ensino (barreiras técnicas, culturais e ergonômicas) para que fossem indicadas atividades que se tornassem soluções viáveis.

Já os principais atributos do m-learning considerados neste estudo foram: (I) a mobilidade; (2) a conectividade e; (3) a experiência personalizada de aprendizagem, que orientaram, juntamente com as questões abordadas anteriormente, as sugestões de atividades do protocolo. A figura 2 apresenta o processo de desenvolvimento do artefato.

\section{APRESENTAÇÃO DO PROTOCOLO}

$\bigcirc$ artefato foi dividido em três etapas (figura 3). A primeira é dedicada à escolha do $m$-learning como método de ensino em relação à IES e ao estudante.A segunda etapa indica os principais desafios a serem enfrentados e as potencialidades a serem aproveitadas. Já a terceira, trata das sugestões de atividades adequadas às diversas situações apresentadas no protocolo.

De acordo com Ferreira et al. (20l3), alguns aspectos devem ser considerados ao

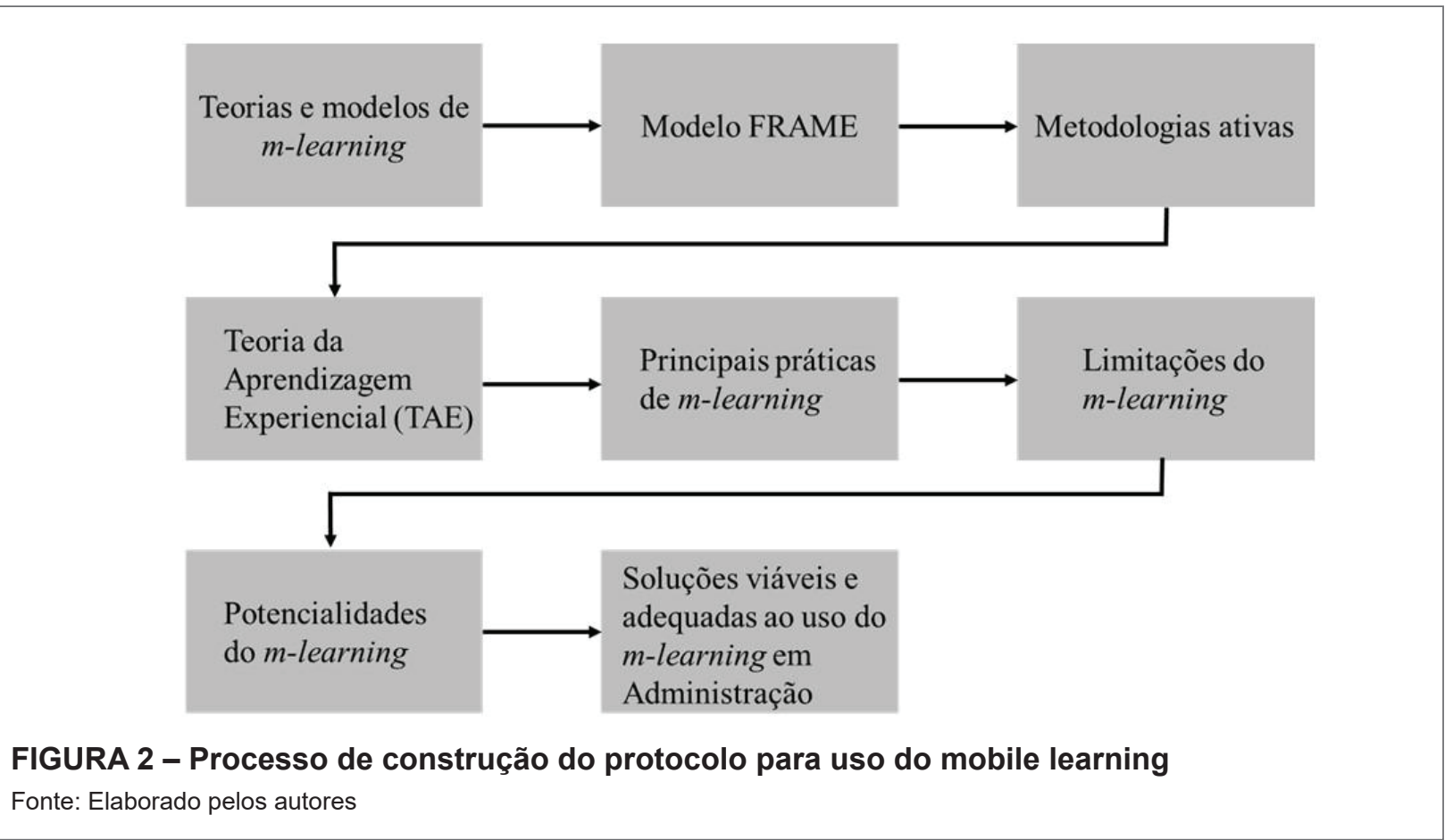

R. Adm. FACES Journal Belo Horizonte v. 17 n. 3 p. 28-47 jul./set. 2018. ISSN 1984-6975 (online). ISSN 1517-8900 (Impressa) 39 http://dx.doi.org/10.21714/1984-6975FACES2018V17N3ART5571 
adotar o mobile learning como modalidade de ensino: (I) a cultura institucional; (2) as informações sobre a área de conhecimento em que será aplicado; (3) as experiências de mobile learning previamente desenvolvidas, bem como os seus resultados; (4) as características do público para quem a metodologia é projetada, incluindo a sua familiaridade com as tecnologias digitais; e (5) as tecnologias disponíveis e aplicações digitais. Esses aspectos foram tratados a partir do questionário Diagnóstico na etapa Conscientização do Problema da Desing Research.

Entretanto, para a construção do artefato, na primeira etapa, em relação à IES, elegeu-se a cultura institucional como item de destaque a ser avaliado. Propõe-se que esta avaliação deva acontecer por intermédio da observação e da verificação de situações e ocorrências que possam dar indícios da existência de uma cultura favorável ao uso dos dispositivos móveis, tais como: a oferta de livre acesso à internet por meio de rede sem fio, com boa qualidade de conexão e em todos os espaços da instituição; o incentivo ao uso da tecnologia móvel integrada à metodologia de ensino; e a existência e divulgação de aplicativos da IES para aparelho celular, disciplinas e atividades online. Já em relação ao aluno, buscou-se avaliar seu perfil, procurando compreender a dinâmica social no campus, os contextos trazidos para sala de aula, a aceitação da tecnologia móvel, além de questões práticas, como saber se todos os estudantes participantes do experimento possuem aparelho celular ou tablet com acesso à internet.

Após a análise do ambiente, na segunda etapa de construção do protocolo, partiu-se para os lidar com os principais desafios e potencialidades do mobile learning apresentados no referencial teórico. Embora as potencialidades tenham sido o ponto de partida desta pesquisa, com as diversas possibilidades de aprendizagem, foram os desafios que nortearam a construção do artefato, em função de uma busca efetiva para atendimento aos critérios de funcionalidade do protocolo. Incialmente, questões técnicas como rede móvel sem fio, qualidade de conexão e acesso dos estudantes foram as principais preocupações. Porém, barreiras culturais como: baixo grau de "alfabetização digital" e resistência ao e-learning, que se estende ao m-learning (SCHLEMMER et al., 2007), se apresentaram como obstáculos mais importantes que as questões de tecnologia ou infraestrutura.

A terceira etapa é dedicada a sugerir abordagens e atividades de mobile learning que tratem os desafios e potencialidades de forma adequada ao ensino de Administração. As sugestões, assim como as demais etapas do artefato, tiveram como base as principais recomendações presentes na literatura sobre aprendizagem móvel (SHARPLES et al., 2007;WINTERS, 2007).

Como na Design Research a construção do conhecimento ocorre simultaneamente ao desenvolvimento da pesquisa (FREITAS JUNIOR et al., 20I5), no decorrer do processo de aplicação dos modelos iniciais de protocolo foram incluídas duas recomendações: (I) uma para que seja incentivada a solução cooperativa de problemas; e (2) outra para que o professor tenha uma postura dialógica e democrática ao usar o m-learning.

Ao observar a dinâmica dos grupos de aprendizagem online por intermédio da análise das mensagens trocadas entre os participantes, percebeu-se que nas equipes em que os problemas foram rapidamente compartilhados e apresentados de forma objetiva como "me digam se devo imprimir

40 R. Adm. FACES Journal Belo Horizonte v. 17 n. 3 p. 28-47 jul./set. 2018. ISSN 1984-6975 (online). ISSN 1517-8900 (Impressa) http://dx.doi.org/10.21714/1984-6975FACES2018V17N3ART5571 
os folhetos em preto e branco ou pagamos mais pelos coloridos" ou "estas (foto anexada) são as fitinhas que têm aqui para vender. O que acham? (...)", os trabalhos finais apresentados por esses grupos foram bem elaborados e a equipe se tornou mais coesa. Já nos grupos em que ocorreu pouca interação e quase nenhuma ideia foi compartilhada, os problemas não foram postos em discussão e os próprios participantes do grupo se mostraram insatisfeitos com o desempenho alcançado.

Em relação ao professor adotar uma postura mais dialógica e democrática, essa recomendação emergiu no grupo focal. Os respondentes destacaram a importância do professor se mostrar disposto a ensinar, mas também a aprender.

“O professor não pode ser arrogante. Não se achar estrelinha. Tem que usar (o grupo do WhatsApp® ou email para se comunicar com alunos) normal. Como uma pessoa qualquer. Não como uma pessoa assim, superior. Se for o bam bam bam, os alunos não vão interagir. Vai ficar ele e a arrogância dele lá, falando sozinho."

\section{ANÁLISE DOS RESULTADOS}

Inicialmente será descrito o perfil dos respondentes, o qual consiste de estudantes do curso de Administração na disciplina de Gestão de Serviços, regime presencial e de turno matutino em que cerca de $58 \%$ são mulheres, $69,7 \%$ dos alunos têm entre 18 e 28 anos e $72 \%$ possuem renda familiar abaixo de $R \$ 3.500,00$ (três mil e quinhentos reais). Pode-se dizer que o grupo de respondentes deste estudo foi composto majoritariamente por jovens da classe $C$ e $D$ (critério do IBGE) que frequentam o ensino superior, permanecem conectados
(84\%) por mais de 12 horas por dia e costumam usar o dispositivo móvel $(88,7 \%)$ em atividades ligadas ao ensino e aprendizagem. Porém, apesar desses números traduzirem o comportamento da maioria dos alunos, ainda existem $4,8 \%$ que não possuem dispositivo móvel conectado à internet. Após uma análise mais aprofundada, nota-se que 7I,4\% dos respondentes declaram preferir aprender com apoio do mobile learning, e, ao mesmo tempo, $27,4 \%$ dos estudantes encontram-se apartados, de alguma forma, do processo de aprendizagem com uso de tecnologia móvel, seja por não possuírem telefone celular com acesso à internet ou por dependerem das redes de conexão móvel dos locais que frequentam.

Essa questão das dificuldades de acesso aos serviços de conexão à internet móvel de qualidade também emergiu dos dados qualitativos como uma desvantagem de uso da tecnologia móvel para apoio ao processo de ensino-aprendizagem. Essa realidade, encontrada no ambiente pesquisado, reforça os achados da literatura adotada, no que diz respeito às limitações do m-learning, mais precisamente em relação às conexões e dispositivos caros e barreiras culturais, como a necessidade de "alfabetização digital" e fortalecimento do hábito de uso dos dispositivos móveis (SACCOL et al., 20I0).

Apesar dessas barreiras, os resultados indicam que os estudantes são favoráveis ao uso dos dispositivos móveis na educação e percebem a contribuição do m-learning para o aprendizado (84,5\%), especialmente devido aos atributos facilidade e rapidez de acesso à informação, ubiquidade, conveniência e interação. Por outro lado, a dispersão/desatenção se apresenta como a principal preocupação dos estudantes (SCHLEMMER et al., 2007). 


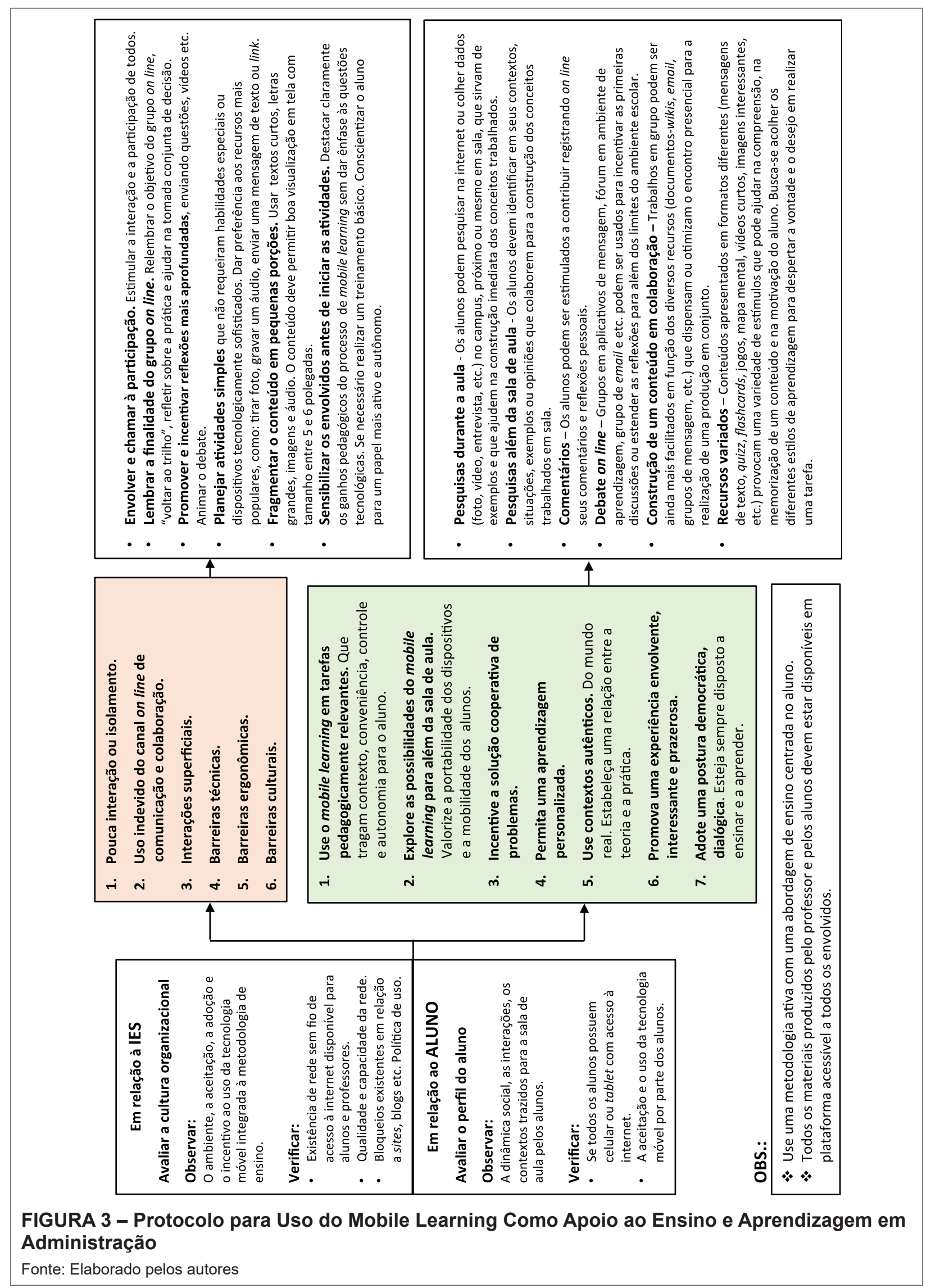

42 R. Adm. FACES Journal Belo Horizonte v. 17 n. 3 p. 28-47 jul./set. 2018. ISSN 1984-6975 (online). ISSN 1517-8900 (Impressa) http://dx.doi.org/10.21714/1984-6975FACES2018V17N3ART5571 
Para o desenvolvimento e análise do artefato (protocolo), desenvolvido com base no modelo FRAME, o quadro 9 descreve cada um dos aspectos e interseções do modelo, indicando quais deles foram identificados neste estudo. As principais questões referentes ao modelo FRAME identificadas foram: conforto e simplicidade de uso do aparelho celular pelo usuário (D e DA); capacidade de contribuição do m-learning para o aprendizado (A e AS); experiência social promovida pelo uso do dispositivo móvel como ferramenta pedagógica (S e DS); e o reconhecimento da contribuição do mobile learning para o aprendizado (DAS). Sendo assim, para todos os aspectos e interseções do modelo foram encontradas evidências no contexto pesquisado, o que sugere a adequação do protocolo proposto para o desenvolvimento de estratégias e atividades de m-learning adequadas ao ensino e aprendizagem em Administração.

$\mathrm{Na}$ sequência faz-se uma discussão sobre os principais desafios encontrados nesta pesquisa, cruzando com referências e estudos anteriores sobre m-learning e resistência à adoção de inovação.

\section{Barreiras: Resistência à Mudança, Bai- xo Grau de Criticidade e Formação do Professor Universitário}

Apesar do resultado positivo encontrado neste estudo, facilitado pelo uso generalizado dos dispositivos móveis em todas as camadas da sociedade e de sua utilização como ferramenta de apoio a aprendizagem por grande parte do alunado, os resultados também apontam barreiras à adoção do $m$-learning, que devem ser consideradas para que a IES venha a adotar políticas e práticas com maiores possibilidades de êxito.

Embora os estudantes reconheçam a possibilidade do uso dessa modalidade na educação superior, além de já adotarem a tecnologia móvel em sua maioria, paradoxalmente se declaram satisfeitos com a metodologia atual e com a forma como os conteúdos são conduzidos pela maioria dos professores da IES $(81,28 \%)$, isto é, aulas basicamente expositivas sem uso de novas tecnologias digitais para auxiliar o processo de ensino-aprendizagem. Além disso, $53,57 \%$ dos respondentes afirmaram não querer que o uso da tecnologia mude sua forma de estudar, nem a maneira como os professores dão aula. Esse resultado pode ser entendido como resistência à mudança na adoção de inovações. Existem diferentes definições desse conceito identificadas na literatura. Contudo, a definição de resistência à mudança de Zaltman e Duncan (1977), que considera as diversas barreiras culturais, sociais, organizacionais e psicológicas à mudança, se mostra mais aderente ao contexto pesquisado, pois entende qualquer conduta para manter o status quo diante da pressão para alterá-lo como resistência. $\bigcirc$ que, de fato, sugere estar mais alinhado com o comportamento encontrado.

Porém, a resistência à mudança não ocorre somente por parte do estudante. Segundo Pina et al. (20l6), é necessário mudar a política e a cultura das instituições e dos docentes, marcadas pelo ensino presencial e por práticas pedagógicas, que, em sua maioria, atribuem ao aluno um papel passivo em relação a sua própria aprendizagem. Vale lembrar que a proposta de uso do m-learning deve ser baseada no construtivismo social. E nessa perspectiva o aluno é visto como agente autônomo capaz de escolher sua trilha e navegar no conhecimento (KOOLE, 2009). Schlemmer et al. (2007) alertam 
QUADRO 9 - Apresentação dos Resultados a partir do Modelo FRAME

\begin{tabular}{|c|c|c|}
\hline Critério & Descrição & Evidências encontradas \\
\hline Dispositivo (D) & $\begin{array}{l}\text { Refere-se às características físicas, } \\
\text { técnicas e funcionais do disposi- } \\
\text { tivo móvel. Essas características } \\
\text { possuem um impacto significativo } \\
\text { sobre os níveis de conforto físico e } \\
\text { psicológico dos usuários. }\end{array}$ & $\begin{array}{l}\text { Sim. Dados quantitativos. } \\
\text { - } 89,28 \% \text { acharam confortável usar o celular para trocar mensagens } \\
\text { com o grupo de trabalho online. } \\
\text { - } 86,57 \% \text { acham simples usar o celular. } \\
\text { - } 83,28 \% \text { consideraram a velocidade do seu celular adequada às } \\
\text { tarefas que precisaram realizar para a disciplina (envio de mensa- } \\
\text { gens, fotos, links, etc.) }\end{array}$ \\
\hline Aluno (A) & $\begin{array}{l}\text { Refere-se às habilidades cogni- } \\
\text { tivas do aluno: a memória; o co- } \\
\text { nhecimento prévio; as emoções; e } \\
\text { as motivações possíveis. Pode-se } \\
\text { fazer uso ativo da informação para } \\
\text { ajudar o aluno a lembrar, entender } \\
\text { e transferir conceitos para contex- } \\
\text { tos variados. }\end{array}$ & $\begin{array}{l}\text { Sim. Dados quantitativos. } \\
\text { - } 87 \% \text { acharam que os recursos usados na disciplina facilitaram a } \\
\text { compreensão do conteúdo (grupo de trabalho online, envio de ví- } \\
\text { deos, etc.) } \\
\text { - } 84,28 \% \text { acharam que as atividades de m-learning propostas ajuda- } \\
\text { ram a selecionar, escolher e reconhecer informações importantes } \\
\text { em diferentes situações (debates online, contato para esclareci- } \\
\text { mento de dúvidas, entre outras). } \\
\text { - } 80,57 \% \text { acharam que as atividades de m-learning propostas deixa- } \\
\text { va-os mais motivados para estudar. }\end{array}$ \\
\hline Social (S) & $\begin{array}{l}\text { Leva em conta os processos de } \\
\text { interação social e de cooperação. } \\
\text { Afeta a quantidade e a qualidade da } \\
\text { comunicação. }\end{array}$ & $\begin{array}{l}\text { Sim. Dados quantitativos. } \\
\text { - } 91,14 \% \text { acharam adequada a maneira como as informações foram } \\
\text { trocadas. } \\
\text { - } 88,42 \% \text { acharam a quantidade de mensagens trocadas adequada. } \\
\text { - } 86,57 \% \text { consideraram que a conversa entre os membros do grupo } \\
\text { ocorreu de forma franca e se sentiram à vontade para participar. } \\
\text { - } 85,71 \% \text { consideraram que houve qualidade nas informações troca- } \\
\text { das no grupo de trabalho online, isto é, as mensagens eram claras } \\
\text { e de compreensão rápida. }\end{array}$ \\
\hline $\begin{array}{l}\text { Usabilidade do } \\
\text { Dispositivo (DA) }\end{array}$ & $\begin{array}{l}\text { Trata da facilidade do usuário de } \\
\text { aprender e conseguir usar o dis- } \\
\text { positivo o mais rápido possível; da } \\
\text { portabilidade do dispositivo; e da } \\
\text { disponibilidade da informação. }\end{array}$ & $\begin{array}{l}\text { Sim. Dados quantitativos. } \\
\text { - } 91,42 \% \text { acham fácil aprender a usar um celular. } \\
\text { - } 86,57 \% \text { acham simples usar um celular. } \\
\text { - } 94 \% \text { acham que, atualmente, existe uma grande quantidade de in- } \\
\text { formação disponível de fácil acesso. }\end{array}$ \\
\hline $\begin{array}{l}\text { Tecnologia Social } \\
\text { (DS) }\end{array}$ & $\begin{array}{l}\text { Como os dispositivos móveis permi- } \\
\text { tem a comunicação e a colaboração } \\
\text { entre várias pessoas e sistemas. }\end{array}$ & $\begin{array}{l}\text { Sim. Dados quantitativos. } \\
\text { - } 88,85 \% \text { acharam que usar o celular para participar das atividades } \\
\text { propostas promoveu oportunidades de compartilhamento de co- } \\
\text { nhecimento. } \\
\text { - } 86,14 \% \text { acharam que usar o celular para participar das atividades } \\
\text { propostas promoveu oportunidades de produção de conteúdo para } \\
\text { a disciplina. }\end{array}$ \\
\hline $\begin{array}{l}\text { Aprendizagem } \\
\text { Interativa (AS) }\end{array}$ & $\begin{array}{l}\text { Refere-se à interação, a cognição } \\
\text { situada e à comunidade de apren- } \\
\text { dizagem. }\end{array}$ & $\begin{array}{l}\text { Sim. Dados quantitativos. } \\
\text { - } 87 \% \text { acharam que o uso do m-learning promoveu oportunidade de } \\
\text { interação. } \\
\text { - } 78,71 \% \text { identificaram no seu dia a dia situações, que representaram } \\
\text { o que foi discutido em sala de aula e nas atividades de m-learning } \\
\text { propostas. } \\
\text { Sim. Dados qualitativos } \\
\text { - Ótima experiência com o grupo de trabalho online (14 citações) }\end{array}$ \\
\hline $\begin{array}{l}\text { Processo } \\
\text { m-learning (DAS) }\end{array}$ & $\begin{array}{l}\text { Refere-se a natureza da própria in- } \\
\text { teração, muda a forma como os alu- } \\
\text { nos interagem entre si, o acesso à } \\
\text { informação e seleção e navegação } \\
\text { no conhecimento }\end{array}$ & $\begin{array}{l}\text { Sim. Dados quantitativos. } \\
\text { - } 84,57 \% \text { acreditam que o uso do m-learning contribuiu para o seu } \\
\text { aprendizado. } \\
\text { - } 90,42 \% \text { acham que a forma como os alunos interagem entre si, } \\
\text { mudou. } \\
\text { Sim. Dados qualitativos } \\
\text { - Recomendariam uma disciplina com uso do m-learning, porque ele } \\
\text { ajuda a entender e a aprender a matéria, é fácil e prático e é inte- } \\
\text { rativo (50 citações). }\end{array}$ \\
\hline
\end{tabular}

Fonte: Elaborado pelos autores. 
também para a urgência no desenvolvimento de uma cultura de aprendizagem e de autonomia por parte das instituições de ensino e dos aprendizes para que consigam fazer a transição do papel passivo para o ativo e para que sejam capazes de construir suas competências para atender seus próprios objetivos educacionais.

Entretanto, para se tornar sujeito de sua aprendizagem, é preciso que o estudante desenvolva um pensamento crítico e reflexivo, e que a IES, por intermédio de seu projeto pedagógico, promova práticas que estimulem o questionamento, o diálogo e a argumentação, tendo como base o contexto do aluno. Conforme descrito no referencial teórico, envolver o estudante e fazê-lo sentir o que está fazendo é tão importante quanto fazê-lo pensar no que está fazendo. Contudo, ensinar um pensamento mais complexo e aumentar o grau de criticidade dos estudantes não é algo simples. Durante a execução desta pesquisa, em diversos momentos e após a análise dos dados, notou-se que grande parte dos estudantes não consegue desenvolver sua percepção e compreensão para além do senso comum, e acabam por reproduzir o pensamento da maioria, deixando de aprofundar suas questões.

Os resultados aqui obtidos permitem também identificar situações em que o aluno descreveu se sentir perdido por ter dificuldade no gerenciamento das informações em função do grande fluxo de mensagens e conteúdos recebidos. Portanto, o docente precisa estar atento à importância de uma gestão da aprendizagem que leve em conta as habilidades cognitivas do aluno, além de um planejamento cuidadoso para o uso e combinação entre modalidades de ensino, presencial, online e $m$-learning, para que não ocorra redundância ou sobrecarga. Por fim, a adoção do m-learning exige uma sólida formação didático-pedagógica do professor para usar a tecnologia móvel de forma a potencializar a aprendizagem (FERREIRA et al., 20I3).

\section{CONSIDERAÇÕES FINAIS}

O objetivo deste estudo foi propor um protocolo para elaboração de estratégias e atividades de $m$-learning para apoiar o processo de ensino e aprendizagem em Administração, a partir da percepção dos estudantes. A principal contribuição deste trabalho foi o desenvolvimento de um artefato que se apresenta como uma ferramenta de aprendizagem capaz de contribuir para a busca de soluções educacionais que envolvam o uso de tecnologias móveis, principalmente devido aos aspectos sociais como interação, promoção de contextos autênticos e formação de comunidades de aprendizagem.

Os resultados da pesquisa apontam evidências que reforçam todos os aspectos e critérios analisados pelo modelo teórico adotado FRAME (KOOLE, 2009). Assim, este estudo apresenta contribuições para a literatura sobre o tema m-learning com dados empíricos, além aprofundar a compreensão sobre o uso dos dispositivos móveis no ensino superior, no âmbito do contexto nacional.

Como contribuição de ordem metodológica, destaca-se a utilização da Design Research como método de pesquisa. Os resultados encontrados indicam que essa metodologia possui uma abordagem adequada para desenvolvimento de pesquisas e sua aplicação prática, auxiliando, por exemplo, em como o m-learning pode ser estudado e desenvolvido na prática.

No tocante aos futuros pesquisadores, professores e gestores de IES que tenham 
interesse em desenvolver estratégias ou atividades de m-learning, foi possível observar que é necessário considerar e respeitar o contexto existente e as práticas educacionais, assim como a cultura das instituições e dos envolvidos no processo de ensino e aprendizagem. É importante ainda compreender que as IESs, principalmente as já estabelecidas, precisam de tempo para inovar e promover mudanças.

Verifica-se por meio dos resultados da pesquisa que as potencialidades do $\mathrm{m}$-learning sugerem a adoção de uma metodologia ativa de aprendizagem, além de uma abordagem de ensino centrada no aluno.

Outra constatação importante é a de que há a necessidade de se verificar o grau de "alfabetização digital" dos participantes, sendo interessante propor um treinamento básico, podendo até ser conduzido por outro aluno mais capacitado, objetivando nivelar os conhecimentos dos alunos em tecnologia móvel.

Observa-se também a necessidade de checar e garantir a qualidade e a abrangência do serviço de conexão à internet móvel da instituição de ensino para que sejam desenvolvidas atividades de $m$-learning adequadas às condições técnicas disponíveis, assim como a obtenção de suporte da instituição para que as possíveis ocorrências sejam conduzidas da forma mais favorável ao desenvolvimento da experiência de uso do m-learning.

Finalmente, os resultados do estudo apontam para o fato de que, ao optar por participar de grupos online, é preciso adotar uma postura democrática e dialógica, estando atento à interação social e cons- ciente de que as relações de autoridade não são necessariamente formais dentro de um grupo online.

Uma das limitações deste estudo foi ter sido realizado em uma turma não exclusiva do curso de Administração de Empresas. Apesar dos resultados refletirem apenas as percepções dos alunos do curso, a turma era também composta por alunos de marketing, ciência da computação e pedagogia. Outra limitação observada foi a aplicação do questionário final de avaliação ter ocorrido na mesma data da última prova do semestre. A possibilidade de estarem presentes todos os participantes da pesquisa foi o motivador dessa estratégia. Entretanto, alguns alunos não responderam ao questionário, declarando falta de tempo hábil para preenchimento do mesmo, em função da necessidade de terminar a prova e ir para o trabalho, diminuindo o índice de respostas.

Como sugestões para futuras pesquisas, acredita-se que a reaplicação do protocolo para realizar um estudo comparativo entre instituições de perfis diferentes de forma a validar e ampliar os resultados aqui encontrados. Outra sugestão seria o uso do protocolo para um estudo de controle. Utilizando-se duas turmas da mesma disciplina da graduação em Administração com características semelhantes, uma delas serviria como grupo de controle, em que nenhuma das condições habituais seriam alteradas e na outra turma se utilizaria o protocolo para verificar se existe alteração de percepção por parte dos estudantes no que se refere ao aprendizado percebido. 


\section{REFERÊNCIAS}

BARDIN, L., Análise de Conteúdo. Lisboa. Persona, 1995.

CHU,H.;HWANG, G.;TSAI, C.;TSENG, J.A two-tier test approach to developing location-aware mobile learning systems for natural science courses. Computers \& Education, v.55, n.4, p.1618-1627, 2010.

FERREIRA,J. B.; KLEIN,A.Z.; FREITAS, A.; SCHLEMMER, E. Mobile Learning: Definition, Uses and Challenges, in Laura A. Wankel, Patrick Blessinger (ed.) Increasing Student Engagement and Retention Using Mobile Applications: Smartphones, Skype and Texting Technologies (Cutting-edge Technologies in Higher Education), v.6, Emerald Group Publishing Limited, p.47-82, 2013.

FREITAS, A. S. A implementação do e-learning nas escolas de gestão: um modelo integrado para o processo de alinhamento ambiental. 2009. $330 \mathrm{f}$. Tese (Doutorado em Administração) - Pontifícia Universidade Católica (PUC), Rio de Janeiro, 2009.

FREITAS, A. S.; BANDEIRA-DEMELLO, R. Managerial action and sensemaking in e- implementation in Brazilian business schools. Computers \& Education, v.59, n.4, p.I.286-I.299, 2012.

FREITAS JUNIOR, J. C. S.; MACHADO, L.; KLEIN,A. Z.; FREITAS,A.S. Design Research: aplicações práticas e lições aprendidas. Revista de Administração FACES, v. I4, n. I, p.95-I I6, 2015.

KEARNEY, M.; BURDEN, K.; RAI, T. Investigating teachers'adoption of signature mobile pedagogies. Computers \& Education, v.80, p.48-57, 2015.
KOLB, D. A. Management and the Learning Process, California Management Review, v.18, n.3, p.2I-3I, 1976.

KOLB, D.A. Management and the Learning Process, California Management Review, v. 18, n.3, p.2I-3I, 1976.

KOLB, D. A. Experiential learning: Experience as the source of learning and development. New Jersey: Prentice-Hall, 1984.

KOOLE, M. L. A Model for Framing Mobile Learning. In: Mobile learning: transforming the delivery of education and training. AU Press, Athabasca University, p.25-47, 2009.

MACHADO, L.; KLEIN, A.; SCHLEMMER, E.; FREITAS, A.S.; PEDRON, C.D. O Uso de Mundos Virtuais Tridimensionais para o Desenvolvimento de Competência Intercultural: uma experiência entre Brasil e Portugal, XII SBGames, São Paulo, p.38-49, 20I3. Disponível em: http://www.sbgames. org/sbgames $2013 /$ proceedings/industria/05-full-paper-indtrack.pdf. Acesso: I 3 de junho de 20 I5.

PINA, F; KURTZ, R.; FERREIRA, J.; FREITAS, A; SILVA, J.; GIOVANNINI, C. Adoção De M-Learning No Ensino Superior: O Ponto De Vista Dos Professores. Revista Eletrônica de Administração, v. 22, n. 2, p. 279-306, ago. 2016.

SACCOL, A. Z.; SCHLEMMER, E.; BARBOSA, J.; HAHN, R. M-learning e U-learning: novas perspectivas da aprendizagem móvel e ubíqua. São Paulo: Pearson Education, 2010.

SCHLEMMER, E.; SACCOL, A.Z.; BARBOSA, J.; REINHARD, $N$.
M-learning ou aprendizagem com mobilidade: casos no contexto brasileiro, $13^{\mathrm{a}}$ Congresso Internacional ABED de Educação a Distância - Curitiba, Paraná, p.I-II, 2007. Disponível em: http://www.abed.org.br/congresso2007/tc/552007 I I 24 I I PM.pdf. Acesso: 10 de outubro de 2015.

SHARPLES, M.; ARNEDILLO, I. S.; MILRAD, M.; VAVOULA, G. Mobile Learning: Small devices, big issues. 2007. Disponível em: http://telearn.noekaleidoscope. org/warehouse/KAL_Legacy_ Mobile_Learning_(00I I43vl).pdf .Acesso: 25 de abril de 2015.

SHIH, Y.E.; MILLS, D. Setting the new standard with mobile computing in online learning. International Review of Research in Open and Distance Learning, v.8, n.2, 2007.

TAKEDA, H.;VEERKAMP, P.;TOMIYAMA, T.; YOSHIKAWAN, H. Modeling design processes. Artificial Inteligence Magazine, v. I , n.4, p.38-45, 1990.

TRAXLER, J. Defining, Discussing, and Evaluating Mobile Learning. International Review of Research in Open and Distance Learning. v.8, n.2. 2007.

WINTERS, N. What is mobile learning. in M. Sharples (Ed.), Big issues in mobile learning. Report. University of Nottingham. 2007. Disponível em http:// www.Isri.nottingham.ac.uk/Publications_PDFs/BIG_ISSUES_REPORT_PUBLISHED.pdf. Acesso: 23 jan. 2015.

ZALTMAN, G.; DUNCAN, R. Strategies for planned change. New York: John Willey and Sons, 1977. 